\title{
Understanding Drug-Protein Interactions in Escherichia coli FabI and Various FabI Inhibitor Complexes
}

\author{
Han Myoung Lee* and N. Jiten Singh \\ Center for Superfunctional Materials, Department of Chemistry, Pohang University of Science and Technology, \\ Pohang 790-784, Korea. *E-mail: abcd0lhm@postech.ac.kr \\ Received October 25, 2010, Accepted November 8, 2010
}

\begin{abstract}
Many ligands have been experimentally designed and tested for their activities as inhibitors against bacterial enoylACP reductase (FabI), ENR. Here the binding energies of the reported ligands with the E. coli ENR-NAD ${ }^{+}$were calculated, analyzed and compared, and their molecular dynamics (MD) simulation study was performed. IDN, ZAM and AYM ligands were calculated to have larger binding energies than TCL and IDN has the largest binding energy among the considered ligands (TCL, S54, E26, ZAM, AYM and IDN). The contribution of residues to the ligand binding energy is larger in $E$. coli ENR-NAD $^{+}$-IDN than in E. coli ENR-NAD ${ }^{+}$-TCL, while the contribution of NAD ${ }^{+}$ is smaller for IDN than for TCL. The large-size ligands having considerable interactions with residues and NAD ${ }^{+}$ have many effective functional groups such as aromatic $\pi$ rings, acidic hydroxyl groups, and polarizable amide carbonyl groups in common. The cation- $\pi$ interactions have large binding energies, positively charged residues strongly interact with polarisable amide carbonyl group, and the acidic phenoxyl group has strong H-bond interactions. The residues which have strong interactions with the ligands in common are Y146, Y156, M159 and K163. This study of the reported inhibitor candidates is expected to assist the design of feasible ENR inhibitors.
\end{abstract}

Key Words: Enoyl-acyl carrier protein reductase, ENR inhibitor, ENR-NAD ${ }^{+}$-ligand interaction, Molecular dynamics

\section{Introduction}

The Escherichia coli (E. coli) is one of the bacterial-diseasecausing parasites. The enoyl-[acyl-carrier-protein] reductase (ENR), an enzyme involved in fatty acid biosynthesis, is known to be a good target for antibacterial drugs. The type II fatty acid synthetases (FAS II) are found in plants and other bacteria not in mammals. Plants and most prokaryotes perform the type II fatty acid synthesis, in contrast to eukaryotes which follow the type I fatty acid synthesis. Mammalian fatty acid synthase (FAS I) is different from FAS II. Fatty acid biosynthesis in bacteria is essential process to produce a number of lipid-containing components including the cell membrane. ${ }^{1}$ The enoyl reductase (ENR), also known as FabI, is one of the key components of the FAS II system. The ENR puts the last hand to the completion of the fatty acid chain elongation cycle by catalyzing the stereospecific reduction of the double bond between $\mathrm{C} 2$ and $\mathrm{C} 3$ positions of a growing fatty-acid chain. ${ }^{2,3}$ Hence, ENR becomes a important drug target for E. coli and other three critical infectious disease problems i.e., methicillin-resistant staphylococcus aureus (MRSA), ${ }^{4}$ Tuberculosis (TB) ${ }^{5}$ and Malaria. ${ }^{6}$

As one of the struggle to get over these diseases triclosan (TCL) has been shown to be effective against a variety of bacteria including Escherichia coli, Staphylococcus aureus, Plasmodium falciparum, and Mycobacterium smegmatis. ${ }^{7}$ Currently, triclosan is widely used antibacterial agent to a variety of consumer products such as toothpastes, mouthwashes, hand soaps, deodorants, lotions, children's toys, cutting boards, and plastic films to wrap meat products. But some mutants of $E$. coli show resistance to this triclosan. ${ }^{8}$ Many biochemical studies for the triclosan activity have been performed on the wild-type (WT) and mutated E. coli ENRs. ${ }^{8-16}$ And as new bacterial ENR inhi- bitors, many ligands have been tested for their inhibitory activities. ${ }^{17-21}$ At first in 1996 Rice's group used diazaborine derivatives as the antibacterial candidate ligand. ${ }^{2,17}$ But these ligands are known to be toxic compounds, and it was investigated on molecular basis study that a flipping loop (I192-S198) of $E$. coli ENR is involved in the active site with triclosan. ${ }^{14}$ In 2001 Heerding's group reported that the 1,4-disubstituted imidazoles are critical and effective inhibitors to FabI activity, ${ }^{18}$ and Seefeld's group tested 2,9-disubstituted 1,2,3,4-tetrahydropyrido $[3,4-b]$ indoles as potential antibacterial agents. ${ }^{19}$ In 2002 Miller et al. discovered aminopyridine-based inhibitors of FabI, ${ }^{20}$ and in 2003 Seefeld et al. reported the test of indole naphthyridinones as inhibitors against bacterial enoyl-ACP reductases FabI and FabK. ${ }^{21}$

It is very important to understand the functional groups and structures of good ligands and the important amino acid residues of the active site of ENR where the ligands would bind with different binding efficacies. Detailed understanding of the structure and energy relationship of these ENR inhibitors could help the design of new and improved ENR inhibitors. Therefore, here we calculated, analyzed and compared the binding energies of the reported ligands with the $E$. coli ENR-NAD $^{+}$, and performed their molecular dynamics (MD) simulation study. In particular we point out the important amino acid residues which are responsible for the improved binding efficacies with the inhibitors.

\section{Computational Methods}

The X-ray structures of $E$. coli ENR-NAD ${ }^{+}$-ligands were obtained from the reported Protein Databank (PDB ID for TCL ligand: $1 \mathrm{C} 14,{ }^{14} \mathrm{PDB}$ ID for S54 ligand: $1 \mathrm{I} 2 \mathrm{Z},{ }^{18} \mathrm{PDB}$ ID for 
E26 ligand: $1130,{ }^{19} \mathrm{PDB}$ ID for ZAM ligand: $1 \mathrm{LX} 6,{ }^{20} \mathrm{PDB}$ ID for AYM ligand: $1 \mathrm{LXC}^{20}$ and PDB ID for IDN ligand: $1 \mathrm{MFP}^{21}$ ). The names of ligands are given as followings: TCL; Triclosan, S54; 4-(2-Thienyl)-1-(4-methylbenzyl)- $1 H$-imidazole, E26; 1,3,4,9-Tetrahydro-2-(hydroxybenzoyl)-9-[(4-hydroxyphenyl) methyl]-6-methoxy-2H-pyrido[3,4- $b$ indole, ZAM; 3-[(Acetylmethyl-amino)-methyl]-4-amino- $N$-methyl- $N$-(1-methyl- $1 H-$ indole-2-ylmethyl)-benzamide, AYM; 3-(6-Aminopyridin-3yl)- $N$-methyl- $N$-[(1-methyl-1H-indole-2-yl)methyl]acrylamide, and IDN; $(E)-N$-Methyl- $N$-(1-methyl-1H-indole-3-ylmethyl)3-(7-oxo-5,6,7,8-tetrahydro-[1,8]naphthyridin-3-yl)-acrylamide. The structures of these ligands are shown in Figure 1. The X-ray structures of 1I30, 1LX6 and 1LXC complexes have the broken losses of amino acids of A197-R204, R193-K205 and A196-D202, respectively. These loss parts are overlapped with the flipping loop (I192-S198) of E. coli ENR. ${ }^{14}$ Each of the X-ray structures of the $E$. coli ENR-NAD ${ }^{+}$-ligands consists of two configurations $\mathrm{A}$ and $\mathrm{B}$.

The ligand molecules were first extracted from the crystal complex structures. Then the ligand geometries were optimized using the B3LYP/6-31G* level of theory with the Gaussian 03 suite of programs. ${ }^{22}$ Single point calculations were then performed to obtain the electrostatic potential at the B3LYP/cc$\mathrm{pVTZ}$ level with the polarized continuum model $(\mathrm{EPS}=4.0)$. Atomic partial charge for the EPSP was computed using the Restrained Electrostatic Potential (RESP) method. ${ }^{23}$ The partial charges and the new parameters used here are given as Supplementary material. From their X-ray structures water molecules which are not hydrogen bonded to any of the protein residues were removed. The geometries were solvated with the truncated octahedron solvation method which gave a more uniform distribution of solvent around the solute. The force field and partial charges of $\mathrm{NAD}^{+}$were taken from the work of Ryde U. and co-workers. ${ }^{24}$ Amber atom types and missing force field parameters of the ligands were assigned using the antechamber in Amber $9 .{ }^{25}$ The binding energies of the ligands were calculated after the energy minimization using the X-ray structures of the E. coli ENR-NAD ${ }^{+}$-ligands. The energy minimizations were performed with molecular mechanics. And we performed the MD simulations for $3 \mathrm{~ns}$ using their energy-minimized struc-
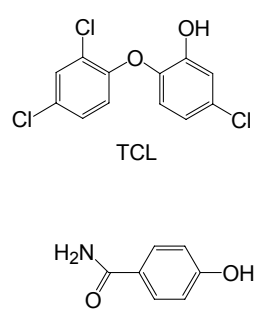

E26

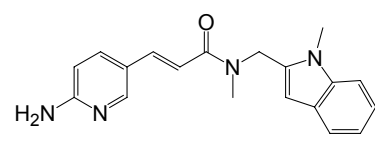

AYM

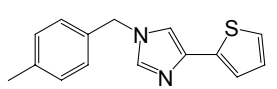

S54
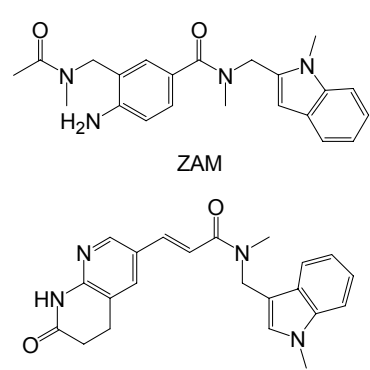

IDN
Figure 1. Structures of six ligands (TCL, S54, E26, ZAM, AYM and IDN). tures. The energy minimizations and MD simulations were carried out using the Amber9 program. ${ }^{25}$ We also calculated the B-factor of the $\alpha$-carbon atoms of the protein of each of the MD trajectories. Their average binding energy calculations were performed for last $1.5 \mathrm{~ns} \mathrm{MD}$ simulations after convergence of total energy.

\section{Results and Discussion}

After the energy minimization the interaction energies of each residue-ligand and $\mathrm{NAD}^{+}$-ligand and total interaction energies of ligands for configurations $\mathrm{A}$ and $\mathrm{B}$ were calculated and presented in Figure 2. And their interaction energy data are listed in Table 1. Among the total interaction energies of ligands (TCL, S54, E26, ZAM, AYM and IDN) the IDN ligand has the largest interaction energies $(-94.57 \mathrm{kcal} / \mathrm{mol}$ for A configuration and $-90.92 \mathrm{kcal} / \mathrm{mol}$ for $\mathrm{B}$ configuration). The ligand interaction energies of ZAM are $-81.16 \mathrm{kcal} / \mathrm{mol}$ for $\mathrm{A}$ and -85.07 $\mathrm{kcal} / \mathrm{mol}$ for $\mathrm{B}$, while the ligand interaction energies of TCL are $-52.52 \mathrm{kcal} / \mathrm{mol}$ for A configuration and $-50.05 \mathrm{kcal} / \mathrm{mol}$ for B configuration. Among the considered ligands IDN, ZAM, AYM and S54 except E26 have larger interaction energies than TCL for each configuration. Really, in the experiments IDN revealed considerably good inhibitory activities against FabI and FabK in comparison with TCL. ${ }^{21}$ Also ZAM and AYM showed acceptable inhibitory activities against FabI in comparison with TCL. ${ }^{20}$

The ratios of the $\mathrm{NAD}^{+}-\mathrm{TCL}$ interaction energy to the total TCL interaction energy are $35.3 \%$ for A configuration and $37.4 \%$ for $\mathrm{B}$ configuration, while the ratios of $\mathrm{NAD}^{+}-\mathrm{IDN}$ are $19.8 \%$ for $A$ and $19.6 \%$ for B. That is, the IDN ligand has many binding sites with protein residues. For A configurations the
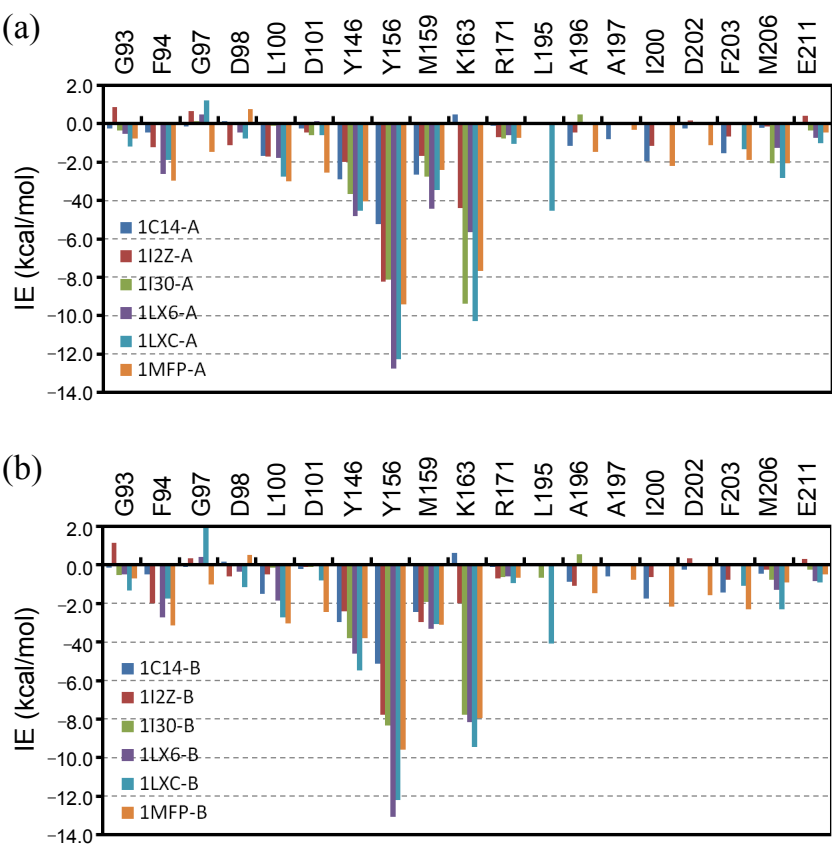

Figure 2. Interaction energies (IE) of the residues which have considerable interactions with ligands for (a) A configurations and (b) B configurations after the energy minimizations. 
Table 1. Interaction energy contributions of important amino acid residues interacting with ligands calculated from the energy minimized complex structures

\begin{tabular}{|c|c|c|c|c|c|c|c|c|c|c|c|c|}
\hline \multirow{2}{*}{ residues } & \multicolumn{6}{|c|}{ A configuration } & \multicolumn{6}{|c|}{$\mathrm{B}$ configuration } \\
\hline & TCL & S54 & E26 & ZAM & AYM & IDN & TCL & S54 & E26 & ZAM & AYM & IDN \\
\hline G93 & -0.24 & 0.86 & -0.34 & -0.52 & -1.20 & -0.76 & -0.16 & 1.16 & -0.52 & -0.48 & -1.32 & -0.70 \\
\hline F94 & -0.44 & -1.22 & 0.00 & -2.62 & -1.90 & -2.98 & -0.50 & -1.98 & 0.00 & -2.72 & -1.74 & -3.14 \\
\hline G97 & -0.16 & 0.66 & 0.12 & 0.50 & 1.22 & -1.46 & -0.12 & 0.36 & 0.02 & 0.40 & 1.92 & -1.02 \\
\hline D98 & 0.12 & -1.12 & -0.06 & -0.44 & -0.78 & 0.76 & 0.18 & -0.58 & -0.02 & -0.36 & -1.14 & 0.52 \\
\hline L100 & -1.66 & -1.70 & -0.12 & -1.78 & -2.74 & -3.00 & -1.50 & -0.50 & -0.14 & -1.86 & -2.72 & -3.04 \\
\hline D101 & -0.24 & -0.44 & -0.58 & 0.14 & -0.60 & -2.56 & -0.20 & -0.12 & -0.10 & -0.06 & -0.82 & -2.44 \\
\hline Y146 & -2.90 & -1.98 & -3.68 & -4.82 & -4.52 & -4.04 & -2.96 & -2.42 & -3.80 & -4.62 & -5.48 & -3.82 \\
\hline Y156 & -5.22 & -8.22 & -8.14 & -12.76 & -12.26 & -9.40 & -5.14 & -7.76 & -8.32 & -13.06 & -12.20 & -9.60 \\
\hline M159 & -2.64 & -1.66 & -2.74 & -4.44 & -3.44 & -2.40 & -2.46 & -2.98 & -1.92 & -3.30 & -3.08 & -3.10 \\
\hline K163 & 0.48 & -4.38 & -9.38 & -5.66 & -10.30 & -7.66 & 0.62 & -2.00 & -7.76 & -8.16 & -9.46 & -7.96 \\
\hline R171 & -0.12 & -0.70 & -0.76 & -0.60 & -1.06 & -0.72 & -0.10 & -0.70 & -0.64 & -0.60 & -0.94 & -0.68 \\
\hline L195 & -0.02 & -0.04 & 0.02 & - & -4.52 & -0.04 & -0.04 & 0.04 & -0.68 & - & -4.08 & -0.02 \\
\hline A196 & -1.14 & -0.46 & 0.48 & - & - & -1.46 & -0.88 & -1.08 & 0.54 & - & - & -1.48 \\
\hline A197 & -0.82 & -0.08 & - & - & - & -0.30 & -0.58 & -0.04 & - & - & - & -0.76 \\
\hline I 200 & -1.96 & -1.16 & - & - & - & -2.20 & -1.74 & -0.62 & - & - & - & -2.16 \\
\hline D202 & -0.26 & 0.18 & - & - & - & -1.12 & -0.26 & 0.34 & - & - & - & -1.56 \\
\hline F203 & -1.54 & -0.66 & - & - & -1.34 & -1.88 & -1.42 & -0.78 & - & - & -1.10 & -2.32 \\
\hline M206 & -0.22 & -0.16 & -2.06 & -1.26 & -2.82 & -2.06 & -0.44 & -0.24 & -0.76 & -1.28 & -2.32 & -0.92 \\
\hline E211 & -0.06 & 0.42 & -0.36 & -0.72 & -1.00 & -0.46 & -0.04 & 0.32 & -0.26 & -0.84 & -0.90 & -0.48 \\
\hline $\mathrm{NAD}^{+}$ & -18.56 & -16.62 & -16.96 & -34.36 & -18.70 & -18.68 & -18.72 & -26.86 & -19.40 & -35.14 & -16.78 & -17.84 \\
\hline Total & -52.52 & -55.35 & -41.82 & -81.16 & -76.25 & -94.57 & -50.05 & -57.79 & -41.56 & -85.07 & -79.58 & -90.92 \\
\hline$\Delta \mathrm{G}^{\mathrm{sol}}$ & -38.53 & -29.91 & -12.75 & -40.80 & -39.32 & -50.40 & -38.05 & -31.18 & -11.89 & -41.38 & -42.37 & -49.12 \\
\hline
\end{tabular}

$\mathrm{NAD}^{+}$-ligand interaction energies are $-18.56 \mathrm{kcal} / \mathrm{mol}$ for TCL, $-16.62 \mathrm{kcal} / \mathrm{mol}$ for S54, $-16.96 \mathrm{kcal} / \mathrm{mol}$ for E26, $-34.36 \mathrm{kcal} /$ $\mathrm{mol}$ for ZAM, $-18.70 \mathrm{kcal} / \mathrm{mol} \mathrm{AYM}$, and $-18.68 \mathrm{kcal} / \mathrm{mol}$ for IDN. And for B configurations the $\mathrm{NAD}^{+}$-ligand interaction energies are $-18.72 \mathrm{kcal} / \mathrm{mol}$ for TCL, $-26.86 \mathrm{kcal} / \mathrm{mol}$ for $\mathrm{S} 54,-19.40 \mathrm{kcal} / \mathrm{mol}$ for E26, $-35.14 \mathrm{kcal} / \mathrm{mol}$ ZAM,-16.78 $\mathrm{kcal} / \mathrm{mol}$ for AYM, and $-17.84 \mathrm{kcal} / \mathrm{mol}$ for IDN. The main interactions of $\mathrm{NAD}^{+}-\mathrm{TCL}$ in the $1 \mathrm{C} 14$ complex are the aromatic(cation)-aromatic $\left[\pi_{\text {cation }}-\pi\right]$ interaction ${ }^{26,27}$ between positively charged nicotinamide ring and 5-monochloro-phenol (MCP) of neutral TCL and the H-bond interaction between the phenoxyl group of MCP and the ribose of NAD ${ }^{+}$. The cation- $\pi$ interaction is considerably strong and the acidic phenolic hydroxyl group also has strong H-bond interaction. For $1 \mathrm{I} 2 \mathrm{Z}$ complexes the NAD ${ }^{+}$-S54 interaction are attributed to the $\pi$-stacking interaction between the thiophene ring of S54 and the electron-poor nicotinamide ring of $\mathrm{NAD}^{+}$and a H-bond interaction between one nitrogen atom of the imidazole ring of S54 and one ribose hydroxyl group of $\mathrm{NAD}^{+}$. But in the B configuration S54 has another H-bond interaction between one hydrogen atom of the imidazole ring of S54 and one of the phosphate groups of NAD ${ }^{+}$. $\mathrm{S} 54$ has larger $\mathrm{BE}$ in the $\mathrm{B}$ configuration than in the A configuration. In the E. coli ENR-NAD ${ }^{+}$-E26 complexes, there are two interactions: the $\pi$ - $\pi$ stacking interaction between the aromatic ring of the 4-hydroxybenzamide (E26) and the nicotinamide ring of $\mathrm{NAD}^{+}$and the $\mathrm{H}$-bond interaction between the amide oxygen of the 4-hydroxybenzamide and the ribose hydroxyl group of $\mathrm{NAD}^{+}$. In $1 \mathrm{LX} 6$ complexes the central amide moiety of ZAM has the H-bond interaction between the oxygen atom of the ZAM amide and the ribose hydroxyl group of $\mathrm{NAD}^{+}$and the $\pi_{\text {cation }}-\mathrm{N}$ interaction between the nitrogen atom of the central amide of ZAM and the nicotinamide ring of $\mathrm{NAD}^{+}$. The carbonyl group of amide moiety is polarisable and has strong H-bond interaction. And the 4-amino group of ZAM has another $\mathrm{H}$-bond interaction with one of the phosphate groups of $\mathrm{NAD}^{+}$. So, among the concerned ligands the ZAM has the largest interaction energies $(-34.36 \mathrm{kcal} / \mathrm{mol}$ for A configuration and $-35.14 \mathrm{kcal} / \mathrm{mol}$ for B configuration) with $\mathrm{NAD}^{+}$. In $1 \mathrm{LXC}$ complexes AYM has a central amide moiety which is engaged in the H-bond interaction between the oxygen atom of the AYM amide and the ribose hydroxyl group of $\mathrm{NAD}^{+}$and the $\pi_{\text {cation }}-\mathrm{N}$ interaction between the nitrogen atom of the central amide of $\mathrm{AYM}$ and the nicotinamide ring of $\mathrm{NAD}^{+}$. In $1 \mathrm{MFP}$ complexes the IDN ligand has similar interactions with $\mathrm{NAD}^{+}$to the AYM ligand. IDN has a central amide moiety which has contribution to the H-bond interaction between the oxygen atom of the IDN amide and the ribose hydroxyl group of $\mathrm{NAD}^{+}$and the $\pi_{\text {cation }}-\mathrm{N}$ interaction between the nitrogen atom of the central amide of IDN and the nicotinamide ring of $\mathrm{NAD}^{+}$.

TCL has the main interactions of a strong $\mathrm{H}$-bond interaction $(-5.22 \mathrm{kcal} / \mathrm{mol}$ for A configuration and $-5.14 \mathrm{kcal} / \mathrm{mol}$ for B) using the hydroxyl group with the phenolic hydroxyl group of Y 156, a $\mathrm{H}-\pi$ interaction using MCP hydrogen with the phenol $\pi$ ring of Y146, a H- $\pi$ interaction using $\pi$ ring of 2,4-dichlorophenyl (DCP) with the terminal thiomethoxy group of M159, and a $\mathrm{H}-\pi$ interaction using $\mathrm{MCP} \pi$ ring with hydrophobic side chain of I200. The acidic phenolic hydroxyl group is a good $\mathrm{H}$ donor as well as a good $\mathrm{H}$ acceptor in the H-bond interaction. S54 involves a strong H-bond interaction $(-8.22 \mathrm{kcal} / \mathrm{mol}$ for $\mathrm{A}$ and $-7.76 \mathrm{kcal} / \mathrm{mol}$ for B) using the unsubstituted imidazole 
nitrogen with the phenolic hydroxyl group of Y156, a cation- $\pi$ interaction using imidazole ring with terminal positively charged protonated amine of K163, and a $\mathrm{H}-\pi$ interaction using hydrogen atoms of thiophene ring with the phenolic $\pi$ ring of Y146. The cation- $\pi$ interaction has considerably large interaction energy $\left(-15.94 \mathrm{kcal} / \mathrm{mol}\right.$ for $\mathrm{Bz}-\mathrm{NH}_{4}{ }^{+},-37.9 \mathrm{kcal} / \mathrm{mol}$ for $\mathrm{Bz}-\mathrm{Li}^{+},-28.0$ $\mathrm{kcal} / \mathrm{mol}$ for Bz-Na ${ }^{+},-18.3 \mathrm{kcal} / \mathrm{mol}$ for $\left.\mathrm{Bz}-\mathrm{K}^{+}\right){ }^{26,28} \mathrm{E} 26$ makes a strong electrostatic interaction $(-9.38 \mathrm{kcal} / \mathrm{mol}$ for $\mathrm{A}$ and -7.76 $\mathrm{kcal} / \mathrm{mol}$ for B) using amide carbonyl group with terminal positively charged protonated amine of K163, a H-bond interaction $(-8.14 \mathrm{kcal} / \mathrm{mol}$ for $\mathrm{A}$ and $-8.32 \mathrm{kcal} / \mathrm{mol}$ for B) using amide carbonyl group with the phenolic hydroxyl group of Y156, a H- $\pi$ interaction using the aromatic $\mathrm{H}$ of the 4-hydroxybenzamide with the phenol $\pi$ ring of Y146, an electrostatic interaction using amide group with the terminal thiomethoxy group of M159, and a H-bond interaction using phenolic hydroxyl group with the thiomethoxy group of M198. The carbonyl group of amide form is polarisable and has strong electrostatic interaction with cation even in long distance. ZAM possesses a $\mathrm{H}-\pi$ and a $\mathrm{H}$-bond interactions $(-12.76 \mathrm{kcal} / \mathrm{mol}$ for $\mathrm{A}$ and $-13.06 \mathrm{kcal} / \mathrm{mol}$ for B) using the aromatic indole $\pi$ ring and the central amide carbonyl group of ZAM with the aromatic $\mathrm{H}$ atom and phenolic hydroxyl group of Y156 respectively, an electrostatic interaction (-5.66 $\mathrm{kcal} / \mathrm{mol}$ for A and $-8.16 \mathrm{kcal} / \mathrm{mol}$ for B) using the central amide moiety with the terminal positively charged protonated amine of K163, a H- $\pi$ interaction $(-4.82 \mathrm{kcal} / \mathrm{mol}$ for A and $-4.62 \mathrm{kcal} /$ mol for B) using $\mathrm{H}$ atoms of methyl groups substituted at indole and at central amide with the phenolic aromatic $\pi$ ring of $Y 146$, an electrostatic interaction $(-4.44 \mathrm{kcal} / \mathrm{mol}$ for $\mathrm{A}$ and $-3.30 \mathrm{kcal} /$ mol for B) using the central amide moiety with the terminal thiomethoxy group of $\mathrm{M} 159$, and a $\mathrm{H}-\pi$ interaction using $\mathrm{H}$ atoms of the terminal methyl group substituted at the terminal amide moiety with aromatic phenyl $\pi$ ring of F94. AYM shares a H- $\pi$ and $\mathrm{H}$-bond interactions $(-12.26 \mathrm{kcal} / \mathrm{mol}$ for $\mathrm{A}$ and -12.20 $\mathrm{kcal} / \mathrm{mol}$ for $\mathrm{B}$ ) using the aromatic indole $\pi$ ring and the central amide carbonyl group of AYM with the aromatic $\mathrm{H}$ atom and phenolic hydroxyl group of Y156 respectively, an electrostatic interaction $(-10.30 \mathrm{kcal} / \mathrm{mol}$ for A and $-9.46 \mathrm{kcal} / \mathrm{mol}$ for B) using the central amide moiety with the terminal positively charged protonated amine of $\mathrm{K} 163$, a $\mathrm{H}-\pi$ interaction $(-4.52$ $\mathrm{kcal} / \mathrm{mol}$ for $\mathrm{A}$ and $-5.48 \mathrm{kcal} / \mathrm{mol}$ for B) using $\mathrm{H}$ atoms of methyl groups substituted at indole and at central amide with the phenolic aromatic $\pi$ ring of $Y 146$, an electrostatic interaction ( $-3.44 \mathrm{kcal} / \mathrm{mol}$ for A and $-3.08 \mathrm{kcal} / \mathrm{mol}$ for B) using the central amide moiety with the terminal thiomethoxy group of M159, a $\mathrm{H}-\pi$ interaction using aromatic $\pi$ ring of aminopyridine moiety with aliphathic $\mathrm{H}$ atoms of $\mathrm{L} 100$, and a $\mathrm{H}-\pi$ interaction using the aromatic indole $\pi$ ring with the terminal thiomethoxy group of M206. The interaction between L195 and AYM was overestimated due to the terminology of carboxyl group by the broken loss of $1 \mathrm{LXC}$ ENR protein. IDN has a $\mathrm{H}-\pi$ and a $\mathrm{H}$-bond interactions $(-9.40 \mathrm{kcal} / \mathrm{mol}$ for $\mathrm{A}$ and $-9.60 \mathrm{kcal} / \mathrm{mol}$ for B) using the aromatic indole $\pi$ ring and the central amide carbonyl group of IDN with the aromatic $\mathrm{H}$ atom and phenolic hydroxyl group of Y156, an electrostatic interaction $(-7.66 \mathrm{kcal} / \mathrm{mol}$ for A and $-7.96 \mathrm{kcal} / \mathrm{mol}$ for B) using the central amide moiety with the terminal positively charged protonated amine of K163, a $\mathrm{H}-\pi$ interaction ( $-4.04 \mathrm{kcal} / \mathrm{mol}$ for A and $-3.82 \mathrm{kcal} / \mathrm{mol}$ for B) using
$\mathrm{H}$ atoms of methyl groups substituted at central amide with the phenolic aromatic $\pi$ ring of $\mathrm{Y} 146$, a $\mathrm{H}-\pi$ interaction using the $\mathrm{NH}$ of aminopyridine moiety with the aromatic phenyl $\pi$ ring of F94, a $\mathrm{H}-\pi$ interaction using aromatic $\pi$ ring of aminopyridine moiety with aliphathic $\mathrm{H}$ atoms of L100, an electrostatic interaction using the central amide moiety with the terminal thiomethoxy group of M159, a H- $\pi$ interaction using the aromatic indole $\pi$ ring with the terminal thiomethoxy group of M206, and a $\mathrm{H}-\pi$ interaction using the aromatic indole $\pi$ ring with aliphathic $\mathrm{H}$ atoms of $\mathrm{I} 200$. And also the TCL, S54 and IDN ligands have considerable H- $\pi$ interactions with A196, A197 and I200 residues. ZAM, AYM and IDN have double interactions with Y156 using indole $\pi$ ring and amide carbonyl group. Y156 has a phenol group. In summary large ligands with many functional groups and aromatic rings have large interaction energies with the ENR protein and NAD ${ }^{+}$. The functional groups engaged in the interactions with the residues and $\mathrm{NAD}^{+}$are large aromatic $\pi$ rings, hydroxyl group, and polarizable amide carbonyl group. ZAM, AYM and IDN ligands have indole and amide moieties in common. AYM has one less carbonyl group than ZAM and IDN. IDN and ZAM ligands have similar functional groups to each other but their locations and structures are different. And it is shown in Table 1 that a flipping loop (I192-S198) is involved in the binding region. For six concerned ligands the residues Y146, Y156, M159 and K163 have strong interactions with the ligands in common. These four residues (Y146, Y156, M159 and $\mathrm{K} 163$ ), $\mathrm{NAD}^{+}$coenzyme and ligands of $1 \mathrm{C} 14,1 \mathrm{I} 2 \mathrm{Z}, 1 \mathrm{I} 30$, 1LX6, 1LXC and 1MFP of A configurations are presented in the superimposed form in Figure 3. In Figure 3 F94 and L100
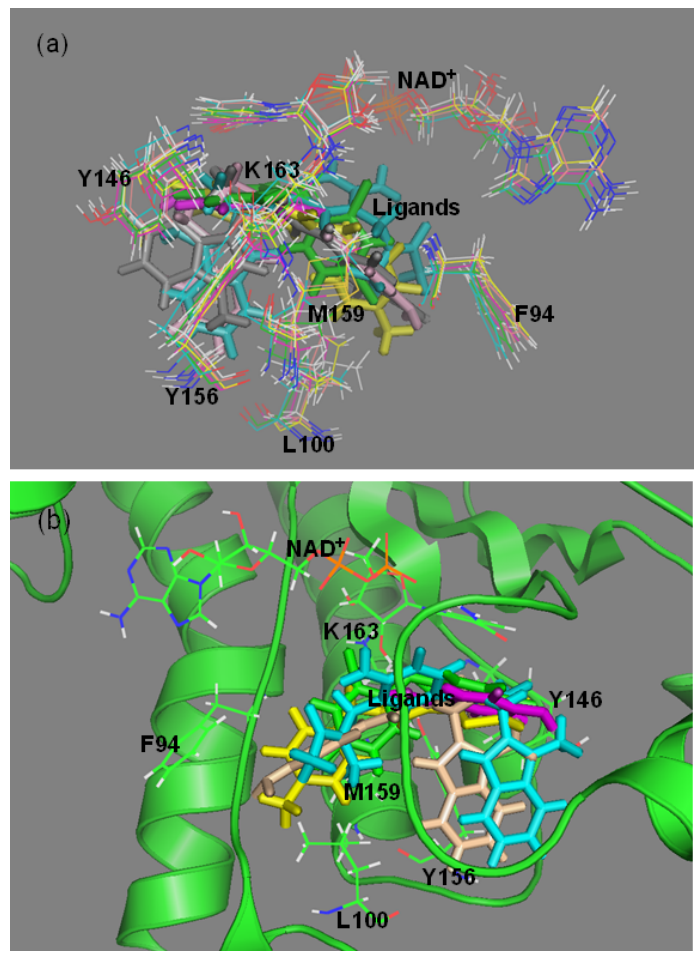

Figure 3. (a) Stick structures and (b) ribbon and stick structures of the main binding sites of ligands in the ENR-NAD ${ }^{+}$-ligand complexes. Six ligands: TCL (green), S54 (yellow), E26 (magenta), ZAM (cyan), AYM (pink) and IDN (grey). 
Table 2. Experimental $\mathrm{IC}_{50}$ values of ligands against $E$. coli. FabI cell lines

\begin{tabular}{lcccccc}
\hline & TCL & S54 & E26 & ZAM & AYM & IDN \\
\hline $\mathrm{IC}_{50}(\mu \mathrm{M})^{a}$ & 0.43 & 13.7 & $>4.2$ & 0.52 & 0.37 & 0.07 \\
Reference & 18,21 & 18 & 19 & 20 & 20 & 21
\end{tabular}

${ }^{a} \mathrm{IC}_{50}$ is the concentration of the ligand for $50 \%$ inhibition of a given biological process such as enzyme activity and in this case is the inhibition of $E$. coli FabI. Ligand molecule with smaller $\mathrm{IC}_{50}$ value has higher binding affinity with FabI and vice versa.

are included. The positions of these six residues and the NAD ${ }^{+}$ coenzyme are little changed. Especially, in the cases of E26, ZAM, AYM and IDN the distances between the nitrogen atom of the protonated amine of K163 and the oxygen atoms of amide carbonyl groups of ligands are even very long as much as 4.56 $6.13 \AA$ but the lysine163 (K163) has strong electrostatic interactions with the amide carbonyl groups of these ligands.

The experimental $\mathrm{IC}_{50}$ values of these ligands against $E$. coli FabI are listed in Table 2. Smaller the value of the $\mathrm{IC}_{50}$, stronger is the inhibitory efficacy of the ligand molecule by means of more strongly binding to the active sites of FabI and vice versa. Although, $\mathrm{IC}_{50}$ values cannot be directly correlated with the free energy changes of the protein-drug complex formation, ligand with lower $\mathrm{IC}_{50}$ is in general associated with the larger change in the free energy of complexation meaning more negative $\Delta \mathrm{G}$ value. Hence, the trends of the $\mathrm{IC}_{50}$ can be correlated with the calculated free changes. In the free energy changes $\left(\Delta G^{\text {sol }}\right)$ with the solvent effect for the ligand bindings in Table 1, TCL has $-38.53 \mathrm{kcal} / \mathrm{mol}$ for A configuration and $-38.05 \mathrm{kcal} / \mathrm{mol}$ for B configuration, which are compatible to the values $(-40.80$ and $-39.32 \mathrm{kcal} / \mathrm{mol}$ for A configurations and -41.38 and -42.37 $\mathrm{kcal} / \mathrm{mol}$ for B configurations) of ZAM and AYM. But the $\Delta \mathrm{G}^{\mathrm{sol}}$, $\mathrm{s}$ $(-50.40 \mathrm{kcal} / \mathrm{mol}$ for A configuration and $-49.12 \mathrm{kcal} / \mathrm{mol}$ for B configuration) of IDN are larger than those of TCL, ZAM and AYM. That is, IDN is a good ligand with large interaction energy. This result is in good agreement with the trend of the experimental $\mathrm{IC}_{50}$ values against $E$. coli FabI as shown in Table 2. The experimental $\mathrm{IC}_{50}$ values against $E$. coli $\mathrm{FabI}$ of TCL, ZAM, AYM and IDN are $0.43,0.52,0.37$ and $0.07 \mu \mathrm{M}$. Through the calculations of the free energy changes $\left(\Delta G^{\text {sol }}\right)$ with the solvent effect the interaction energies of TCL, S54, E26, ZAM, AYM and IDN decreased by $26.6 \%, 46.0 \%, 69.5 \%, 49.7 \%, 48.4 \%$ and $46.7 \%$ in A configurations, respectively. And in B configurations their interaction energies decreased by $24.0 \%, 46.0 \%$, $71.4 \%, 51.4 \%, 49.1 \%$ and $46.0 \%$, respectively. The decrease of the interaction energies of TCL is relatively low in comparison with other ligands. TCL has smaller number of polar functional groups than any of the other ligands. But the interaction energy decrease of small-size E26 ligand is relatively high.

We performed the MD simulations for A configurations of E. coli ENR-NAD ${ }^{+}$-ligand for $3 \mathrm{~ns}$, where ligand is TCL, S54 and IDN. The average interaction energies of ligands were calculated for last $1.5 \mathrm{~ns} \mathrm{MD}$ simulations after convergence of total energy and presented in Figure 4. The interaction energy data are listed in Table 3. After MD simulations the main binding sites were not changed in general, but the conformational change of
Table 3. Interaction energy contributions of important amino acid residues interacting with ligands TCL, S54, and IDN) calculated for last $1.5 \mathrm{~ns}$ of the $3 \mathrm{~ns}$ MD simulations of A configurations

\begin{tabular}{cccc}
\hline residues & TCL & S54 & IDN \\
\hline G93 & -0.18 & 0.50 & -0.54 \\
F94 & -0.56 & -1.48 & -2.94 \\
D98 & -0.08 & -0.58 & 0.58 \\
L100 & -1.02 & -1.08 & -2.34 \\
D101 & -0.26 & -0.32 & -1.36 \\
Y146 & -2.96 & -2.00 & -4.66 \\
N155 & 0.04 & 0.02 & -1.42 \\
Y156 & -3.92 & -5.94 & -9.34 \\
M159 & -3.36 & -3.28 & -2.54 \\
K163 & 0.40 & -5.04 & -6.12 \\
R193 & 0.18 & -0.18 & 1.14 \\
L195 & -0.04 & -0.04 & -0.02 \\
A196 & -0.86 & -1.12 & -1.28 \\
A197 & -0.54 & -0.18 & -0.66 \\
S198 & -0.06 & -0.06 & 0.06 \\
I200 & -1.66 & -2.84 & -1.84 \\
D202 & -0.16 & 0.42 & -1.30 \\
F203 & -1.14 & -1.14 & -3.10 \\
M206 & -0.32 & -0.06 & -1.60 \\
D211 & 0.08 & 0.30 & -0.56 \\
NAD & -17.16 & -11.80 & -10.96 \\
Total & -49.49 & -50.00 & -80.51 \\
$\Delta G^{\text {sol }}$ & -34.88 & -26.14 & -45.50 \\
\hline
\end{tabular}

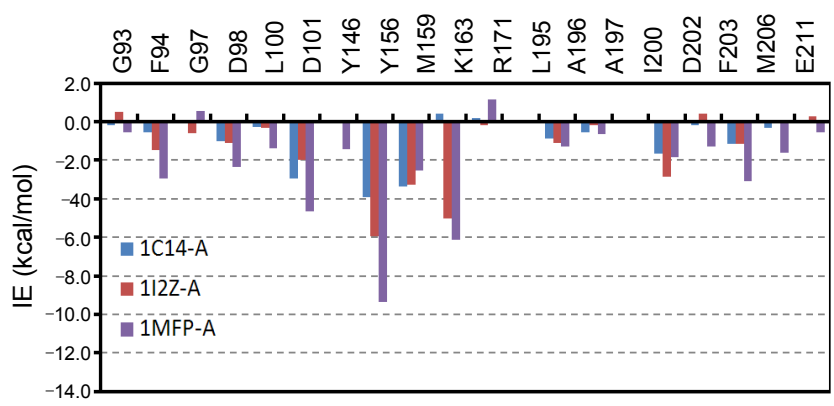

Figure 4. Average interaction energies (IE) of the residues which have considerable interactions with ligands (TCL, S54 and IDN) in A configurations for last $1.5 \mathrm{~ns}$ in the $3 \mathrm{~ns}$ MD simulations.

IDN-F203 H- $\pi$ interaction into $\pi-\pi$ stacking interaction, in which the interaction energy increased from $-1.76 \mathrm{kcal} / \mathrm{mol}$ to $-3.10 \mathrm{kcal} / \mathrm{mol}$, was observed. For $\pi$-stacking interaction is maximal when two $\pi$-rings are displaced by forming a half overlapped sandwich. ${ }^{29,30}$ The $\pi-\pi$ stacking interaction is known to be compatible to the $\mathrm{H}-\pi$ interaction according to their substituents. $^{31,32}$ From the MD simulations the total interaction energies of ligands decreased by $5.8 \%$ for TCL, $9.7 \%$ for S54 and 14.9\% for IDN case. And the $\mathrm{NAD}^{+}$-ligand interaction energies decreased by $7.5 \%$ for TCL, $29.0 \%$ for S54 and $41.3 \%$ for IDN case. This means that the decrease of total ligand interaction energies stems from the decrease of $\mathrm{NAD}^{+}$-receptor interaction energies. But the IDN ligand has the largest total interaction energy $(-80.51 \mathrm{kcal} / \mathrm{mol})$ even after the MD simulations. These total interaction energy of IDN is larger than the total interaction 

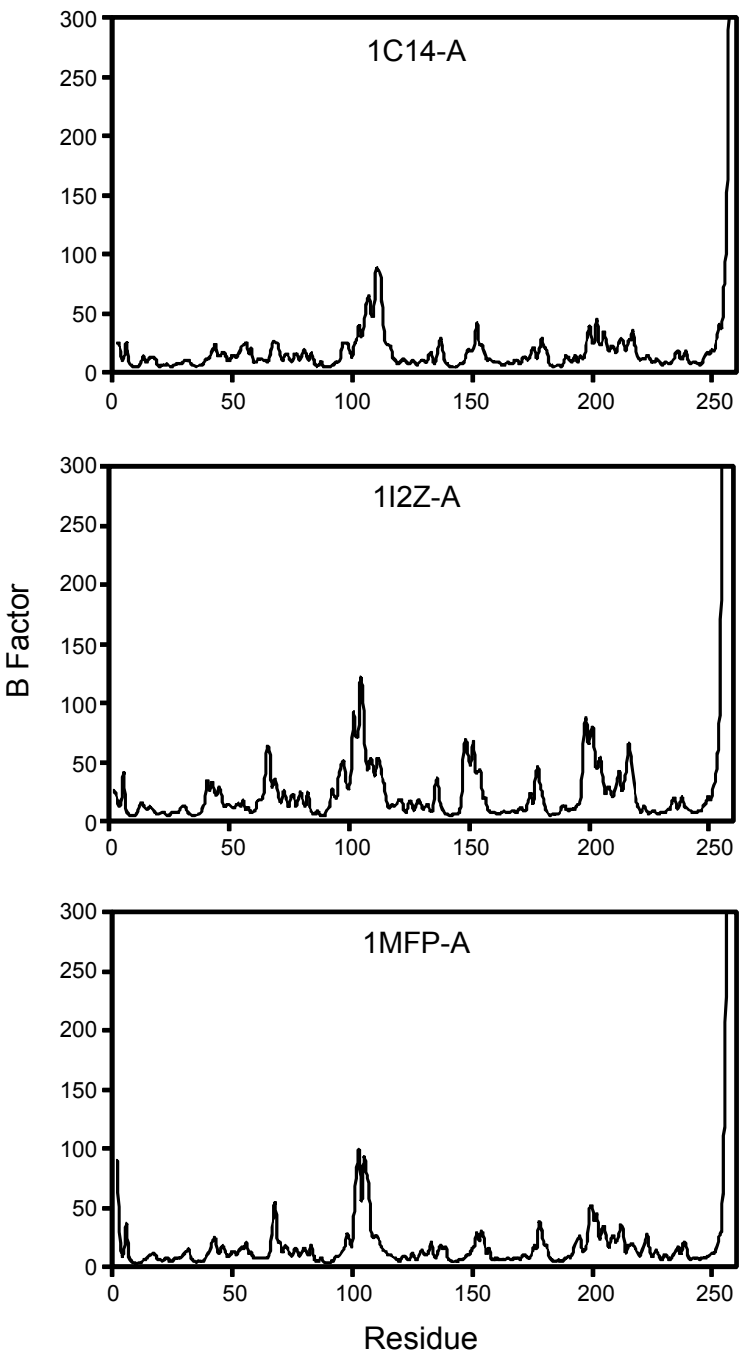

Figure 5. B-factors of residues of $E$. coli ENR-NAD ${ }^{+}$-ligands for the 3 ns MD simulations.

energy of TCL. The total interaction energy $(-50.00 \mathrm{kcal} / \mathrm{mol})$ of S54 is compatible to that $(-49.49 \mathrm{kcal} / \mathrm{mol})$ of TCL. But the free energy change $(-45.50 \mathrm{kcal} / \mathrm{mol})$ with the solvent effect of only IDN is larger than that $(-34.88 \mathrm{kcal} / \mathrm{mol})$ of TCL. This trend agrees with the experimental results as shown in Table 2.

Figure 5 shows the B-factors from the MD simulations of E. coli ENR-NAD ${ }^{+}$-ligands. In the $E$. coli ENR-NAD ${ }^{+}$-TCL complex the I192-S198 loop was known to be flexible for the docking of TCL ligand. ${ }^{14}$ As shown in Figure 3 the B-factors of the residues of this loop and the residues in its vicinity have generally large values. The residues around L100-A115 and E150 make helical structures, which have relatively large B-factors but they are located aloof from the ligands. The residues Y156, K163, Y146 and M159 which have strong interactions with the ligands in common were gauged to show relatively small B-factors.

\section{Conclusions}

In the experiments actually IDN ligand is known to have considerably good inhibitory activities against FabI and FabK in comparison with TCL. ${ }^{21}$ And ZAM and AYM were proposed to show reasonable inhibitory activities against $E$. coli FabI. ${ }^{22}$ Through the energy minimizations and molecular dynamics simulations it is understood that ZAM and AYM ligands have large interaction energies with ENR-NAD ${ }^{+}$complex of E. coli FabI which are compatible to the interaction energy of TCL ligand and IDN has larger interaction energy than TCL, ZAM and AYM. This result agrees well with the experimental inhibitory activities against $E$. coli $\mathrm{FabI}$. The experimental $\mathrm{IC}_{50}$ values against $E$. coli FabI of TCL, ZAM, AYM and IDN are $0.43,0.52,0.37$ and $0.07 \mu \mathrm{M}$. For TCL ligand the ratio of $\mathrm{NAD}^{+}-$ ligand interaction energy to the total interaction energy of ligand is $36.4 \%$ on average, but for IDN ligand the average ratio is $19.7 \%$. The contribution of residues to the ligand binding is larger in $E$. coli ENR-NAD $^{+}$-IDN than in E. coli ENR-NAD $^{+}-$ TCL. The large-size ligands with many functional groups and aromatic rings are calculated to have large interaction energies with the ENR protein and $\mathrm{NAD}^{+}$coenzyme. The functional groups of ligands which have considerably strong interactions with residues and $\mathrm{NAD}^{+}$are aromatic $\pi$ rings, acidic hydroxyl groups, and polarizable amide carbonyl groups. IDN, ZAM and AYM ligands have indole and amide moieties in common. For the six handled receptors the residues Y156, K163, Y146 and M159 strongly interact with the ligands in common. The side chain of Y145 and Y156 is phenol group, M159 thiomethoxy group and $\mathrm{K} 163$ positively charged protonated amine. In general, the cation- $\pi$ interactions including $\pi_{\text {cation }}-\pi$ interaction have stronger interactions and also cations have strong interactions with polarisable carbonyl group. And the acidic phenolic hydroxyl group has strong H-bond interactions. IDN and ZAM ligands have similar functional groups to each other but their locations and structures are different. We hope that this information would be useful in the design of ENR inhibitors.

\section{References}

1. Kruh, N. A.; Borgaro, J. G.; Ruzsicska, B. P.; Xu, H.; Tonge, P. J. J. Biol. Chem. 2008, 283, 31719 .

2. Baldock, C.; Rafferty, J. B.; Sedelnikova, S. E.; Baker, P. J.; Stuitje, A. R.; Slabas, A. R.; Hawkes, T. R.; Rice, D. W. Science 1996, 274, 2107.

3. Heath, R. J.; Li, J.; Roland, G. E.; Rock, C. O. J. Biol. Chem. 2000, $275,4654$.

4. Priyadarshi, A.; Kim, E. E.; Hwang, K. Y. Proteins 2010, 78, 480.

5. Gagneux, S.; Long, C. D.; Small, P. M.; Van, T.; Schoolnik, G. K.; Bohannan, B. J. M. Science 2006, 312, 1944.

6. Hall, N.; Karras, M.; Raine, J. D.; Carlton, J. M.; Kooij, T. W. A.; Berriman, M.; Florens, L.; Janssen, C. S.; Pain, A.; Christophides, G. K.; James, K.; Rutherford, K.; Harris, B.; Harris, D.; Churcher, C.; Quail, M. A.; Ormond, D.; Doggett, J.; Trueman, H. E.; Mendoza, J.; Bidwell, S. L.; Rajandream, M. A.; Carucci, D. J.; Yates, J. R.; Kafatos, F. C.; Janse, C. J.; Barrell, B.; Turner, C. M. R.; Waters, A. P.; Sinden, R. E. Science 2005, 307, 82.

7. Kapoor, M.; Gopalakrishnapai, J.; Surolia, N.; Surolia, A. Biochem. J. 2004, 381, 735. Perozzo, R.; Kuo, M.; bir Singh Sidhu, A.; Valiyaveettil, J. T.; Bittman, R.; Jacobs, Jr., W. R.; Fidock, D. A.; Sacchettini, J. C. J. Biol. Chem. 2002, 277, 13106.

8. McMurray, L. M.; Oethinger, M.; Levy, S. B. Nature 1998, 394, 531.

9. Heath, R. J.; Yu, Y. T.; Shapiro, M. A.; Olson, E.; Rock, C. O. J. Biol. Chem. 1998, 273, 30316. 
10. Levy, C. W.; Roujeinikova, A.; Sedelnikova, S.; Baker, P. J.; Stuitje, A. R.; Slabas, A. R.; Rice, D. W.; Rafferty, J. B. Nature 1999, 398, 383.

11. McMurry, L. M.; McDermott, P. F.; Levy, S. B. Antimicrob. Agents Chemother. 1999, 43, 711.

12. Slater-Radosti, C.; Van Aller, G.; Greenwood, R.; Nicholas. R.; Keller, P. M.; DeWolf, W. E., Jr.; Fan, F.; Payne, D. J.; Jaworski, D. D. J. Antimicrob. Chemother. 2001, 48, 1.

13. Levy, S. B. Emerg. Infect. Dis. 2001, 7, 512.

14. Qiu, X.; Janson, C. A.; Court, R. I.; Smyth, M. G.; Payne, D. J.; Abdel-Meguid, S. S. Protein Sc. 1999, 8, 2529.

15. Takahata, S.; Iida, M.; Yoshida, T.; Kumura, K.; Kitagawa, H.; Hoshiko, S. J. Antibiol. 2007, 60, 123.

16. Oliveira, J. S.; Pereira, J. H.; Canduri, F.; Rodrigues, N. C.; de Souza, O. N.; de Azevedo, W. F.; Basso, L. A.; Santos, D. S. J. Mol. Biol. 2006, 359, 646.

17. Baldock, C.; Rafferty, J. B.; Sedelnikova, S. E.; Bithell, S.; Stuitje, A. R.; Slabas, A. R.; Rice, D. W. Acta Cryst. 1996, D52, 1181.

18. Heerding, D. A.; Chan, G.; Dewolf, W. E., Jr.; Fosberry, A. P.; Janson, C. A.; Jaworski, D. D.; McManus, E.; Miller, W. H.; Moore, T. D.; Payne, D. J.; Qiu, X.; Rittenhouse, S. F.; Slater-Radosti, C.; Smith, W.; Takata, D. T.; Vaidya, K. S.; Yuan, C. C. K.; Huffman, W. F. Bioorg. Med. Chem. Lett. 2001, 11, 2061.

19. Seefeld, M. A.; Miller, W. H.; Newlander, K. A.; Burgess, W. J.; Payne, D. J.; Rittenhouse, S. F.; Moore, T. D.; DeWolf, W. E., Jr.; Keller, P. M.; Qiu, X.; Janson, C. A.; Vaidya, K.; Fosberry, A. P.; Smyth, M. G.; Jaworski, D. D.; Slater-Radosti, C.; Huffman, W. F. Bioorg. Med. Chem. Lett. 2001, 11, 2241.

20. Miller, W. H.; Seefeld, M. A.; Newlander, K. A.; Uzinskas, I. N.; Burgess, W. J.; Heerding, D. A.; Yuan, C. C. K.; Head, M. S.; Payne, D. J.; Rittenhouse, S. F.; Moore, T. D.; Pearson, S. C.; Berry, V.; DeWolf, W. E., Jr.; Keller, P. M.; Polizzi, B. J.; Qiu, X.; Janson, C. A.; Huffman, W. F. J. Med. Chem. 2002, 45, 3246.
21. Seefeld, M. A.; Miller, W. H.; Newlander, K. A.; Burgess, W. J.; DeWolf, W. E., Jr.; Elkins, P. A.; Head, M. S.; Jakas, D. R.; Janson, C. A.; Keller, P. M.; Manley, P. J.; Moore, T. D.; Payne, D. J.; Pearson, S.; Polizzi, B. J.; Qiu, X.; Rittenhouse, S. F.; Uzinskas, I. N.; Wallis, N. G.; Huffman, W. F. J. Med. Chem. 2003, 46, 1627.

22. Frisch, M. J.; Trucks, G. W.; Schlegel, H. B. et al. GAUSSIAN 09, Revision A.02, Gaussian, Inc.: Pittsburgh, PA, 2009.

23. Bayly, C. I.; Cieplak, P.; Cornell, W. D.; Kollman, P. A. J. Phys. Chem. 1993, 97, 10269.

24. Holmberg, N.; Ryde, U.; Bulow, L. Protein Eng. 1999, $12,851$.

25. Case, D. A.; Darden, T. A.; Cheatham, T. E., III.; Simmerling, C. L.; Wang, J.; Duke, R. E.; Luo, R.; Merz, K. M.; Pearlman, D. A.; Crowley, M.; Wlker, R. C.; Zhang, W.; Wang, B.; Hayik, S.; Roitberg, A.; Seabra, G.; Wong, K. F.; Paesani, F.; Wu, X.; Brozell, S.; Tsui, V.; Gohlke, H.; Yang, L.; Tan, C.; Mongan, J.; Hornak, V.; Cui, G.; Beroza, P.; Mathews, D. H.; Schafmeister, C.; Ross, W. S.; Kollman, P. A. AMBER 9, University of California: San Francisco, 2006.

26. Kim, K. S.; Tarakeshwar, P.; Lee, J. Y. Chem. Rev. 2000, 100, 4145.

27. Singh, N. J.; Min, S. K.; Kim, D. Y.; Kim, K. S. J. Chem. Theory. Comput. 2009, 5, 515.

28. Kim, K. S.; Lee, J. Y.; Lee, S. J.; Ha, T. K.; Kim, D. H. J. Am. Chem. Soc. 1994, 116, 7399

29. Hunter, C. A.; Sanders, J. K. M. J. Am. Chem. Soc. 1990, 112, 5525.

30. Kim, K. S.; Suh, S. B.; Kim, J. C.; Hong, B. H.; Lee, E. C.; Yun, S.; Tarakeshwar, P.; Lee, J. Y.; Kim, Y.; Ihm, H.; Kim, H. G.; Lee, J. W.; Kim, J. K.; Lee, H. M.; Kim, D.; Cui, C.; Youn, S. J.; Chung, H. Y.; Choi, H. S.; Lee, C.-W.; Cho, S. J.; Cho, J.-H.J. Am. Chem. Soc. 2002, 124, 14268 .

31. Lee, E. C.; Hong, B. H.; Lee, J. Y.; Kim, J. C.; Kim, D.; Kim, Y.; Tarakeshwar, P.; Kim, K. S. J. Am. Chem. Soc. 2005, 127, 4530.

32. Lee, E. C.; Kim, D.; Jurečka, P.; Tarakeshwar, P.; Hobza, P.; Kim, K. S. J Phys. Chem. A 2007, 111, 3446. 